\title{
End of Entomologica Fennica
}

https://doi.org/10.33338/ef.87179

In 2005, when Matti Koivula, one of the editors of this journal at the time, introduced me to the readers as the new editor-in-chief (Entomol. Fennica 16: 1), I felt confident about the future of the journal. During the years since, Entomologica Fennica has published a wide range of articles, following new discoveries on the field of entomology in the Palaearctic region. However, now Entomologica Fennica has come to a crossroads, where its publication as an independent journal cannot be continued. To me it feels something like losing a good friend, the end of a fruitful cooperation with nice players, including coeditors, authors, reviewers and members of the Editorial Board, all of whom I want to thank for the shared years.

After fifteen years of editorship, I am approaching the age when some of us feel that everything on earth was better before. Indeed, the environment (s. lat.) of producing a journal has changed considerably since I started as an editor. Consequently, also Entomologica Fennica faced new challenges - financial, competitive, etc. - which after all were, if not impossible to deal with, at least beyond the capabilities of the publishing team to overcome, given that all of them have been volunteers alongside their full time jobs. One of our final efforts was to digitize all old articles of Entomologica Fennica and we are pleased that all articles ever published in the journal are now available as open access for the entomological research community worldwide.

When I had to decline manuscripts that were not within the scope of Entomologica Fennica, I wished the authors good luck with their manuscript in some other journal. Now, I once more encourage authors to submit their manuscripts to another journal and hope that it will be Annales Zoologici Fennici, whose scope, along with the ending of Entomologica Fennica, has been expanded to include Entomology.

Kai Ruohomäki Editor-in-Chief 

